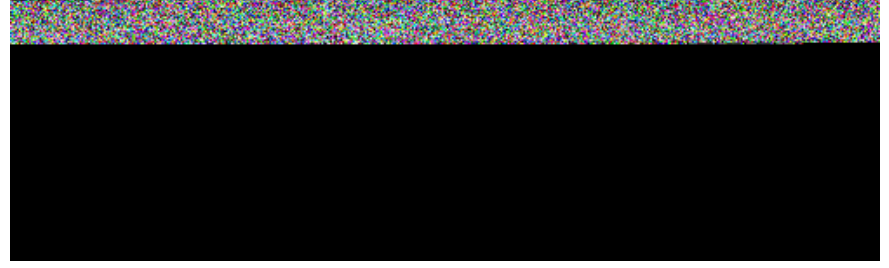

This information is current as of April 26, 2023.

\title{
Do You Need a Coach? I Do
}

AJNR Am J Neuroradiol 2015, 36 (6) 1015-1017 doi: https://doi.org/10.3174/ajnr.A4295

http://www.ajnr.org/content/36/6/1015 


\section{Do You Need a Coach? I Do}

\author{
(iD) M. Castillo, Editor-in-Chief
}

I recently reached an anniversary of sorts; during the 2015 Symposium Neuroradiologicum in Istanbul, Turkey, I gave my 900th invited lecture. Those who were there witnessed what I think were 2 unexceptional lectures. Why? I practiced each about 10 times before the meeting and thought I knew them well. The truth is that sadly, I am not a natural speaker. When I think about gifted speakers, Drs Thomas Naidich and Anne Osborn immediately come to mind. We participate in several events every year, and many times I have seen Dr. Naidich sitting in the first row, building his next conference and immediately thereafter delivering it flawlessly. I will never be able to do that; for me "practice makes perfect" and sometimes as in the Symposium, it does not. Because I think that I know my conference topics well, perhaps my delivery needs work. Maybe I talk too fast (yes, I am certain of that), maybe my body posture needs adjustment (not sure about this but gesticulating does keep nervousness at bay), or maybe I do not make enough eye contact with the audience. A million things can go wrong, but how to improve the most urgent ones is not clear to me. Would coaching help? I think that it would be helpful if someone were to film me and then constructively criticize how my lectures went. When one lectures as much as I do and feels the responsibility of representing one's institution, journal, and professional societies, one worries about the usual stuff public figures do, but the difference is that most (and other not-so-public figures) have coaches who help them refine their deliveries and image.

In his essay "Personal Best," Dr Atul Gawande begins with the following quotation (credited to Barry Blitt, an author and illustrator for the New Yorker magazine): "No matter how well trained people are, few can sustain their best performance on their own. That is where coaching comes in." ${ }^{1}$ Dr Gawande stated that after 8 years as a surgeon, his performance in the operating room (OR) reached a plateau, so he decided to try a coach. He contacted a surgeon he admired and asked him to evaluate his OR behavior. The coach pointed out several needed improvements, and once implemented, Gawande asked to be re-assessed. He also recorded his operations and later watched them with his coach. Of course, I imagine Gawande to be very selfassured and not easily hurt by criticisms. However, regardless of how he felt at the time of his coaching, he concluded that his OR skills improved.

If surgeons, athletes, musicians, singers, chess players, and public speakers, among others, have coaches, why not we radiologists? Today, excellence reigns among musicians, and the word "genius" has lost most of its importance. Most musicians and most professional athletes are excellent at what they do, and the difference between the excellent and truly great is not visible to the untrained like me. Coaching is about self-improvement and

http://dx.doi.org/10.3174/ajnr.A4295 achieving perfection; thus, it may be a lifetime activity for the coach and coachee. Coaching strives to make us better without the addition of drugs, implants, and other "enhancements." Coaching is also a highly specialized activity often requiring not 1 individual but a team of professionals. For athletes, their coaching teams are formed by scientists, physicians, nutritionists, administrators, journalists, engineers, stylists, and many more. ${ }^{2}$ Because winning in sports is nowadays a matter of milliseconds, every little bit counts. Coaching also prevents bad habits from forming and those already there from becoming routine, but coaching is not mentoring. Mentoring is defined as "the relationship between an older more experienced individual with a younger less experienced person with the goal of developing the career of the latter." 3 Mentoring seldom involves payments, while coaching does, and I think that mentoring is a much more complex and difficult relationship (not to say overall less successful).

Let me now discuss some elements of coaching. The International Coaching Federation (http://www.coachfederation.org/) counts over 20,000 members (coaches) and offers several levels of certification (associate, professional, master, and so forth). Most of its activities, but not all, are at the executive levels and have spun considerable data. What follows is a summary of some of that literature (in the financial world, performance and profitability before and after coaching are easily measured indicators). Coaching is akin to psychotherapy as far as human contact goes, but it differs from it by being highly focused and concentrating on the present and future rather than the past. ${ }^{3}$ While a patient generally pays a therapist, in coaching, an organization generally handles the costs, thus inserting at least a third person into the relationship. Both coaching and psychotherapy, however, try to change behavior. Coaching results in improved performance, commitment, efficacy, and leadership. An effective coachcoachee relationship depends on good mutual communication, trust, collaboration, and commitment to the process. After an initial observation stage, the coach provides feedback on performance and potential. These evaluations continue throughout the coach-coachee relationship and thus constantly serve to refine it. The second stage is implementation, and though the coachee ceases to be under constant observation, he or she continues to meet regularly with the coach to discuss obstacles and successes, thus learning to exert some control over the items that need improvement. As if all of this is not complex enough, we need to bring back into the scene the third person previously mentioned. A coach-coachee relationship in which a supervisor (or, in general, the working environment) is not actively invested in the process is bound to fail. For coaching to succeed, the supervisor must believe from the start that it will and encourage both coach and coachee when improvements and changes are achieved.

Many academic radiology programs have some type of mentorship program, and from what I know about them, most are failures. With the help of American Society of Neuroradiology (ASNR) and the American Roentgen Ray Society (ARRS), this 
year we started 2 mentoring pilot projects trying to match senior and junior individuals in both societies. Although the final data are not in, the ASNR part has been only moderately successful and its ARRS counterpart less so. While one does not have to admire a coach, I feel that one must admire a mentor for the relationship to work. Self-choosing a mentor is critical, and that is why our pilots with ASNR and ARRS have not worked well (for the ASNR one, I attempted to match mentors with mentees). Therefore, here is my first proposal: Ask our larger organizations to establish coaching programs akin to what the financial institutions do. One or more senior radiologists could observe our senior residents, fellows, and attendings (at all levels) at work and coach them to become better radiologists. Alternatively, this could be done by using video capture. Real work situations could be evaluated for knowledge, safety, quality, education, collegiality, and efficacy and take the place of the complex general and specialty certifications and all that is needed to maintain them as valid. Scheduled visits, evaluations, and feedback could take the place of re-certifications; my feelings are that the current requirements to obtain these certifications really do not make us better radiologists because we all tend to keep up with knowledge, while at the same time, we design very poor-quality improvement programs, which in the end are of no use to anyone.

Coaching may also be useful beyond our clinical practices. After my significant involvement with 2 scientific societies (ASNR and ARRS), I have come to perceive succession for their key positions as a great challenge. If we think of our nonprofit organizations as families, perhaps it would be helpful to look at how coaching helps in the succession of family businesses. Difficulties found in our organizations are similar to those of family-run businesses: competition, ego, and jealousy, just to mention a few. However, we also share many positive features: values, commitment, legacy, and a desire to survive. Using data from 630 family-owned and -run companies, a study concluded that coaching had a greater influence on the performance of these businesses than mentoring. ${ }^{4}$ In these situations, short and focused coaching was cheaper than mentoring and showed immediate changes in professional performance and skill development. Individuals who were coached also performed successfully when they took over those businesses. My second proposal is that once our larger scientific societies have identified those individuals who eventually will become their leaders, why not hire coaches for them? The current process of mentoring those individuals and making them spend years (sometimes decades) as members of boards and councils does not always work; we are all aware of many chosen nonprofit leaders who were not prepared for the jobs.

Now back to where I started. I do not believe that public speaking coaching is for everyone. If you only give occasional lectures and most are case presentations to your residents, there is no need to go overboard and try to find a coach. However, if you are, like me, delivering some 50 invited lectures per year and still unsure if you are doing it well, some help may be useful. Public speaking coaches will rapidly tell you 2 things: Lecturing is a fact of life for most people (especially educators), and yes, most people are afraid of it (admittedly I still get nervous sometimes but have not been able to identify what triggers it). I Googled "coaching for public speakers" and got more than 15 million hits. Reading the material found in the first 3 pages just confused me; many feel that coaching is essential (the opinion of most who sell those services), and some feel that it is not (these generally recommend recording your voice and image and self-coaching). The same did not happen when I Googled "vocal coaching" with emphasis on opera singers (they have consistently and reliably used coaches for a very long time). Opera coaching strives to extend vocal range and add projection to the voice (I like the part about adding "projection" because I feel that the voices of most academic lecturers do not project well), smooth out vocal wobbles and cracks (I have been trying to do this with the help of a glass of water on the podium), prepare for concerts, sing without straining, and other more technical stuff that does not apply to us (adding squillo, removing vibrato, and so forth) as well as recovering your voice after trauma. Some coaches (especially those residing in other countries) offer coaching via Skype. Coaching opera is difficult because the science of voice and the art of performance are intermingled. Yet that is exactly what I do when I get up to the podium to lecture, a combination of voice and person. Voice and performance are the 2 main factors by which any public speaker is judged. To those, one has to add knowledge when judging our academic lecturers. To me, there is no simple way of self-evaluating these 3 aspects, so does it make sense that at least some of us would benefit from coaching?

\section{REFERENCES}

1. Gawande A. Personal best: top athletes and singers have coachesShould you? New Yorker. October 3, 2011. http://www.newyorker. com/magazine/2011/10/03/personal-best. Accessed November 19, 2014

2. Surowiecki J. Better all the time: how the "performance revolution" came to athletics-and beyond. New Yorker. November 10, 2014. http://www.newyorker.com/magazine/2014/11/10/better-time. Accessed November 19, 2014

3. Baron L, Morin L. The coach-coachee relationship in executive coaching: a field study. Hum Resource Dev Q 2009;20: 85-106

4. Utrilla Nuñez-Cacho P, Torraleja FA. The importance of mentoring and coaching for family businesses. $J$ Manag Organ 2013;19:386-404

\section{Exit and Thanks}

By the time this short note appears, I will be at the threshold of the exit door, nearly completing my 8 -year tenure as the Editor-in-Chief of the American Journal of Neuroradiology (AJNR). I would be remiss not to thank at least some key individuals who have helped and labored with me during this period.

Two equally important teams deserve my appreciation: my support at headquarters: Karen Halm (managing editor), Jason Gantenberg (electronic publications manager), and now retired, Mary Harder (editorial assistant); and the second team, my Senior Editors: Harry Cloft, Nancy Fischbein, Jeff Ross (new AJNR Editor-in-Chief), Pam Schaefer, Charlie Strother, Jody Tanabe, Lucien Levy (now deceased), and Bill Dillon. My eternal gratitude goes to both teams. I am proud of the state of the journal, and they should be, too. 
My mentors, Drs. Bob Quencer, Tom Naidich, Michael Huckman, and Joe Lee, have always offered support and constructive criticisms. All 4 of them and their families are dear to my heart.

It is simply impossible to thank everyone, that being the reason why this note is short (if I did, I doubt I could stop). To those who are not mentioned here, you are not forgotten and I thank you for all you did for AJNR.

Last, I thank my family and especially Hortensia, who have been very patient while I spent countless hours together with AJNR (disappearing into a "black hole" as it is known at home). 